\title{
A critical review of the ethical and legal issues in human germline gene editing: Considering human rights and a call for an African perspective
}

\author{
B Shozi, LLB, LLM \\ African Health Research Flagship, School of Law, College of Law, University of KwaZulu-Natal, Durban, South Africa
}

Corresponding author: B Shozi (214511633@stu.ukzn.ac.za)

\begin{abstract}
In the wake of the advent of genome editing technology CRISPR-Cas9 (clustered regularly interspaced palindromic repeat (CRISPR)associated protein 9), there has been a global debate around the implications of manipulating the human genome. While CRISPR-based germline gene editing is new, the debate about the ethics of gene editing is not - for several decades now, scholars have debated the ethics of making heritable changes to the human genome. The arguments that have been raised both for and against the use of genetic technologies in human reproduction reiterate much of the arguments made in the pre-CRISPR debate. As such, it is instructive for South Africa to reflect on these arguments now, in considering our position on the regulation of the use of this novel biotechnology. There are two dominant schools of thought in this area, bioliberalism and bioconservatism. Bioconservatives raise concerns about the risks of genetic manipulation, and argue that it ought to be limited or prohibited to avert these risks to human health and human nature. Bioliberal scholars are more open to the prospect of genetic manipulation, because of its potential utility. In this article, I conclude that in liberal democracies such as our own, bioliberal arguments ought to be seriously considered when formulating policy on human genome editing because of the extent to which they resonate with our Constitutional values and human rights. I further suggest that there is a need for an enquiry into the relevance of African perspectives on the ethical questions that arise concerning germline genome editing.
\end{abstract}

S Afr J Bioethics Law 2020;13(1):62-67. https://doi.org/10.7196/SAJBL.2020.v13i1.709

In 2012, a group of scientists in the USA published the first article on a novel biotechnology derived from bacteria, which could be used to make precise changes to specific locations in the genome. ${ }^{[1]}$ This technology, called CRISPR-Cas9 (clustered regularly interspaced palindromic repeat (CRISPR)-associated protein 9) ${ }_{1}^{[2]}$ has since generated a significant amount of attention in the scientific community, academia and popular media alike, because of its potential application in humans. This is because it provides a cheap, efficient and relatively precise means of modifying the genome, and could be used to remove specific genes or to insert new ones. ${ }^{[2]}$ While CRISPR-Cas9 has undoubtedly garnered the most attention, it is but one of the many biotechnologies which may be used in germline gene editing at some point. ${ }^{[3]}$ CRISPR-Cas9 has shown a great deal of promise as a possible means for curing previously incurable, debilitating genetic diseases such as Huntington's chorea, Tay Sachs disease and cancer. ${ }^{[4]}$ While much of the attention this technology has garnered is due to the prospect of these unprecedented therapeutic gains becoming a reality within the foreseeable future, much of the discourse around CRISPR-Cas9 has centred on concern about the similarly unprecedented risks this technology brings with it. ${ }^{[5,6]}$

In the wake of the advent of CRISPR-Cas9, there have been numerous calls for the use of this technology to be halted, either permanently or temporarily. The first such call for a moratorium on CRISPR-Cas9 came from the scientific community, at the 2015 International Summit on Human Genome Editing, which concluded that a moratorium on both research and clinical application of germline genome editing (GGE) was necessary because it would be irresponsible to proceed with using CRISPR-Cas9 until its safety and efficacy had been established, and a social consensus was achieved..$^{[7]}$ Shortly after this, the National Institutes of Health $(\mathrm{NIH})$ in the USA ${ }^{[8]}$ declared that it 'will not fund any use of gene-editing technologies in human embryos', citing reservations about the ethics of 'altering the germline in a way that affects the next generation without their consent,' and a current lack of medical applications that justify GGE. ${ }^{[8]}$ More recently, the World Health Organization (WHO) issued a public statement that 'it would be irresponsible at this time for anyone to proceed with clinical applications of human germline editing. ${ }^{[9]}$ Given that CRISPR-based genome editing has been at the centre of the recent debate on GGE at a global level, the present article will focus on this particular genetic technology, and consider its implications for South Africa (SA).

While CRISPR-Cas9 is new, debate on the ethics of gene editing is not. In 1972, Paul Berg refined his technique for using viruses to insert fragments of DNA from other organisms into the genome of bacteria to create recombinant DNA. ${ }^{[10]}$ And from the moment Berg's so-called 'gene-chimaera' experiments became practically feasible, people's minds turned to the possibility of using similar genetic manipulation techniques in humans, and questions were raised about the social, political and ethical implications of doing so. However, it is only recently that the possibility of using biotechnology to alter the human genome has become a probability, and these once abstract debates have become more relevant than ever before. In light of this 
new development, questions have been raised about the ethical and legal permissibility of heritable genome editing in SA. The legality of gene editing in SA has been described as 'ambiguous..[1] This is because our law has no provisions directly relating to germline gene editing. However, section 57(1)(a) of the National Health Act No. 61 of $2003^{[12]}$ does prohibit the manipulation of 'any genetic material, including genetic material of human gametes, zygotes or embryos.'[12] It is not clear whether this provision applies to all forms of genetic manipulation, or just to human reproductive cloning. As such, there is clearly a need for regulatory reform on the law relating to GGE in $\mathrm{SA}$, to provide clarity.

In the course of this policy reform, it is imperative for policymakers, scholars and ordinary South Africans to reflect not only on the current arguments around GGE, but the broader history of the debate on the genetic manipulation of future persons. To this end, this article provides a high-level review of arguments both for and against GGE in the pre-CRISPR debate. It highlights some critical issues that emanate from this debate that are relevant to the SA context. It does not endeavour to outline the entirety of the myriad and diverse views on this controversial issue that have emerged over the last few decades. Instead, the article seeks to provide an overview of the dominant schools of thought on the regulation of GGE, in order to inform and encourage broader debate on the issue today.

\section{Editing the human genome: a line not to be crossed?}

The big question at the centre of the global discourse on the ethics of GGE is whether prospective parents ought to be allowed to choose to have children with modified genomes, or whether heritable change to the human genome is a line that ought not to be crossed. There are a myriad diverse views in this area - which range between these poles - but certain trends have emerged in arguments that are made either for or against GGE. Those holding the latter view often shrink away from the prospect of using genetic technologies in human reproduction because of moral reservations about going against 'nature' or 'playing God.[5] In expressing such reservations, GGE has often been equated to state-sponsored eugenics programs of early 20th century Britain, the USA and Nazi Germany, which had the agenda of eradicating the 'unfit' while encouraging the 'fit' to reproduce. ${ }^{[13]}$ These claims labelling the use of genetic technologies by prospective parents as the new, 'liberal' eugenics evoke powerful imagery that invites repudiation of these innovations. ${ }^{[14]}$ Proponents of so-called liberal eugenics respond to this parallel to Nazi eugenics that what was wrong with eugenics practices was unrelated to the aspiration of making biological changes that benefit future generations (such as by freeing them of genetic diseases), and rather that the means used to achieve this suppressed liberty, by depriving individuals of reproductive choice. ${ }^{[15]}$ This, it is argued, is dissimilar to how it is expected that GGE will actually be used in liberal democracies, which it is argued will enhance procreative liberty by broadening the reproductive choices parents can make. That being said, there has been extensive debate about what limits (if any) the state ought to impose on parental choice when it comes to GGE. It is widely held that while genetic alterations to treat heritable diseases or disability are morally justifiable because they are done for a 'therapeutic' purpose, using genome editing technology to effect changes such as higher intelligence is not, because they constitute genetic 'enhancement.. ${ }^{\text {[16] }}$ The problem with this characterisation, however, is that it is at times difficult to discern what potential genetic modifications are therapeutic, and which are not, and thus views on acceptable genetic modifications may vary significantly. ${ }^{[17]}$

Despite GGE arguably promoting the freedom of prospective parents, many scholars hold the view that there is something ethically problematic about parents making decisions that determine the genetic characteristics of their prospective children. ${ }^{[18,19]}$ One such scholar, Jürgen Habermas, ${ }^{[13]}$ argues that genome editing is objectionable because it entails a perversion of the parentchild dynamic in that it amounts to the instrumentalisation of the prospective child. In a similar vein, Harold Baillie ${ }^{[20]}$ argues that genetic modification objectifies the prospective child and, in removing the element of wonder that comes with not being able to determine who or what a child will be, one forgets the 'serendipity of life.'

Arguments of this kind tend to rely on the Kantian principle known as the categorical imperative, which demands that individuals should always be treated as ends, not merely means. John Harris ${ }^{[21]}$ contends that the interpretation these arguments give to the categorical imperative is a blunt application thereof, which, if one were to take it seriously, leads to absurd conclusions. To illustrate, he argues that applying the categorical imperative as being opposed to all forms of deriving some benefit at the expense of others would require that we also prohibit blood transfusions, notwithstanding that it would cost millions of people their lives. Enunciating what he argues is a proper interpretation of the Kantian principle, Harris opines that one cannot equate deriving benefits from a person - such as receiving a blood transfusion - to treating him or her as a mere means to an end. Similarly, a parent satisfying his or her desire to have a child with particular genetic characteristics does not necessarily mean they are treating that child as a mere means to an end, and thereby violating the categorical imperative.

Scholars who make arguments in the way of Baillie ostensibly place significant stock in the idea that parent-child relationships are based on the genome of the child being a product of chance and not choice. The reason for this, according to Habermas, is that parental discretion ought not to intrude upon a child's ethical freedom, that is, the right of a child to a sense of self-identity - which is intimately connected to certain biological foundations, including the child possessing an unmanipulated genetic inheritance. ${ }^{[13]}$

There are two major criticisms of the argument that GGE is impermissible because prospective persons are entitled to unaltered genomes. Firstly, the argument assumes that using genetic technologies to modify the genome of a potential child is meaningfully different from the other ways in which parents may influence the traits of their offspring, which are currently accepted as permissible. Paul Rabinow ${ }^{[22]}$ highlights the problem with this assumption: the capacity of prospective parents to make decisions concerning their child's genetic characteristics is not an unusual one. Even before the advent of genetic technologies, humans have engaged in what is described as 'selectionist genetics' through the sexual section of partners based on them possessing desirable traits. As with selection using genetic technologies, the goal of selectionist genetics is to pass desired characteristics to offspring, but unlike genetic technologies, the methods of selectionist genetics are slow and inefficient. By using genetic technologies, prospective parents are now able to select traits to pass on to offspring with greater 
precision. They have the ability to introduce traits not present in the genomes of either parent - and it is this higher level of control that Rabinow observes as causing genetic selection to be perceived as being more problematic than sexual selection.

To what extent this perception is justified speaks to the second criticism of the aforementioned argument: it ascribes moral significance to the genome, based on the idea that because genes are foundational to our biology, they are foundational to our identity as humans. This assumption is representative of a trend that has emerged in the era of genomics - much as the concept of the eternal soul was once seen as embodying the essence of what it means to be human, the genome has come to be viewed as a secular equivalent. [23] The claim that genes are fundamental to human identity is problematic as it overemphasises the extent to which genes influence who a person is. It is at this point trite that individuals are a product of not only their genes (i.e. nature) but also their environment (i.e. nurture).

Habermas ${ }^{[13]}$ endeavours to justify why he perceives GGE as more objectionable than other methods of genetic trait selection: he argues that in the case of genetic modification there is a 'collision' between a prospective parent's interest in determining the nature of the prospective person, and that prospective person's self-identity. This, he argues, is different from the way in which other exercises of parental choices, such as sexual selection, impact on the prospective child's sense of identity. This, it is argued, is because by using genetic technologies to choose the genetic characteristics of their potential child, parents determine a fundamental aspect of the child's identity for them. Accordingly, the prospective child will never have the opportunity to undo these aspects of their identity that his or her parents have chosen for them.

It is not apparent that this explains why the act of choosing to use genetic technologies to influence a child's identity is different from using private schooling or drugs such as Ritalin, in any ethically relevant way. It might be true that genetically modified children could not (entirely) undo their genetic endowments. Still, these children could engage in revisionary reflection on what that genetic modification means to them, and their self-perception. ${ }^{[24]}$ It is not necessarily the case that for genetically modified children, the fact that they are genetically modified will be central to their sense of who they are.

\section{The bioconservative perspective}

While there are many who share Habermas' apprehensions about genetic modification and its implications for what it means to be human, generally speaking, even those who are sceptical of genetic technologies concede that their use may be permissible in certain circumstances. ${ }^{[25]}$ What conditions justify the use of genetic technologies is, however, a contested topic, which often turns on the concept of human nature. Francis Fukuyama ${ }^{[26]}$ presents the view that modern biotechnology poses a threat because 'it will alter human nature and thereby move us into a 'posthuman' stage of history.' But what exactly is human nature, and why is it worth preserving?

Fukuyama defines human nature as 'the sum of the behaviour and characteristics that are typical of the human species, arising from genetic rather than environmental factors. ${ }^{[26]}$ By his account, this species-typical behaviour is worth preserving because our perspectives of right and wrong find their roots in human nature - and if we were to lose our human nature (or some critical part of it), we would lose the ability to make essential value judgements. Applying this conceptualisation of human nature can be challenging, as it is difficult to ascertain what exactly typical human behaviour is. ${ }^{[27]}$ Similar to Habermas, this argument places reliance on genetic determinism as a basis for attributing moral significance to the genome and the human behaviours that are a product of genes.

As alluded to above, genetic determinism refers to the notion that just as DNA is foundational to human biology, it is also foundational to human moral worth. ${ }^{[28]}$ Therefore, the commercialisation, cloning and manipulation of human genetic material are morally equivalent to the commercialisation, cloning and manipulation of human persons. This is a concept that had previously abounded in debates about cloning ${ }^{[29]}$ The core claims of the genetic determinism argument may be expressed in the following way:

(i) Human beings have intrinsic moral worth

(ii) Possessing a human genome is what makes you a human being

(iii) Therefore, the human genome has intrinsic moral worth.

As such, cloning a human embryo (which contains a unique genetic code, and which may become a person with said genetic code) is the same thing as 'creating a Xerox copy of a person! ${ }^{\text {[30] }}$

To attribute moral significance to genes is, however, problematic for several reasons. For instance, the claim that human species-typical behaviour - as a result of human genes - is deserving of some manner of special consideration could be criticised as being nothing more than what Peter Singer ${ }^{[3]]}$ describes as 'speciesism' - an irrational bias in favour of one's own species. This is because there is nothing unique to the human genome that would warrant special moral significance.

Using the concept of human nature as a basis for ethical guidance is evidently difficult - despite its rhetorical appeal, it is an ephemeral concept with no clear meaning, and this impairs its usefulness as an ethical standard. ${ }^{[32]}$ Notwithstanding this, bioethics has seen the emergence of a school of thought centred on the concept of human nature, which Ronald Bailey describes as 'bioconservative. ${ }^{\text {[15] }}$ He characterises bioconservatives as aiming to restrict the use of biotechnology, 'because biotech innovation threatens their devoutly held notions of human nature, their social and political views, and their ideas of proper community control'.

A definitive feature of bioconservative arguments is the significant weight they place on the necessity of avoiding these threats. This is sought to be achieved through regulation based on the precautionary principle. ${ }^{[33]}$ There are several formulations of the precautionary principle, and no singular definition of it exists, ${ }^{[34]}$ but a feature common to most formulations is that they proceed from the premise that the kind of risk presented by the use of genetic technologies is unique. This new risk, it is argued, warrants a departure from the usual mechanisms of how we determine whether a particular health intervention should be made available to the public - that is, by weighing probable risks against probable gains. ${ }^{[35]}$ This is necessary because, according to bioconservatives, determining if and when genetic manipulation is appropriate using conventional methods of risk assessment gives too little weight to the nature of the threat to human nature and future generations. This is because these risks are difficult to quantify, or statistically improbable..$^{[28,29]}$

For proponents of the precautionary principle, even a minimal risk of the threats that they fear may come to pass if genetic technologies 
become widely used is too great, and we ought to ban them outright, or adopt a temporary moratorium until the risks associated are fully understood. The challenge to the idea that we should stop and wait, however, is that it is not clear that we will ever be able to understand the risks of GGE in humans without first experimenting with GGE in humans. ${ }^{[25]}$

\section{The bioliberal perspective}

While bioconservatives consider human nature as a basis for limiting genetic modification, other scholars have responded to these arguments also by appealing to human nature, but giving this concept a meaning that is more open to permitting the use of biotechnology (including genetic technologies). Bioconservatives have been critiqued for presenting human nature as a finite set of traits that humans currently display and as something we ought to preserve, which is not representative of the fact that human beings have historically moved away from species-typical behaviour, in order to achieve advancements such as longer lives and better health. ${ }^{[17]}$

Those who reject the bioconservative account of human nature as something to be preserved argue that few traits are as synonymous with humans as pursuing gains by going against nature, because human nature as it exists leaves much to be desired, and there is good reason to want to alter it. For these scholars - whom I term 'bioliberals' - this aspect of human nature is exemplified in the myth of the Greek titan Prometheus, who went against the will of the Olympian Gods to bring fire to humankind. This allegory is alluded to in the works of bioliberal authors such as Ronald Dworkin ${ }^{[36]}$ and Gregory Stock. ${ }^{[37]}$ In contrast to the bioconservative approach, by the bioliberal account, acting in accordance with human nature necessitates that we pursue the use of genetic technologies, because of the positive potential they possess.

In response to the claims that using genetic technologies in reproduction may have deleterious consequences for the prospective child, such as being subject to stigma for being genetically modified, Harris ${ }^{[21]}$ points out that at this point these concerns are mere speculation, and completely disregard the possibility of social learning allowing humanity to adapt to any changes that do materialise. Rather than seeking, in futility, to block or limit these technologies, Stock ${ }^{[37]}$ opines that our energies should be directed at determining the best way to regulate genetic technologies to realise their benefits while minimising their risks and protecting our fundamental freedoms.

The defining feature of bioliberal arguments is their regard for the libertarian principle that the freedom of individuals should not be limited without just cause. ${ }^{[38]}$ As Robertson ${ }^{[39]}$ observes, libertarianism in reproduction means that a person has the right to select for specific genes, or do anything that he or she chooses in the course of becoming a parent. This approach applies the right to procreative liberty - which Robertson ${ }^{[40]}$ views as extending to new reproductive technologies - to GGE.

The bioliberal approach to the use of genetic technologies is that the rights of parents in reproduction give them a prima facie entitlement to modify the genomes of their prospective children, and that claims that GGE should be limited based on sentiments such as the sanctity of life are untenable because such subjective value judgements do not constitute just cause to limit these rights. ${ }^{[32,36]}$ Some bioliberal scholars even go as far as claiming that we have a moral duty to modify prospective persons genetically. ${ }^{[42]}$

\section{Human rights and heritable genome editing}

Several activities related to gene editing potentially fall within the Constitutionally protected interests of several parties in liberal democracies such as SA, including scientists and medical researchers, prospective parents and the children who may be born with a modified genome. ${ }^{[43]}$ And yet human rights have often been overlooked or underplayed in the global debate around CRISPR-Cas9.

Of particular import in this regard are the reproductive rights of the prospective parents who would be choosing to have a genetically modified child. Of the various ethics statements on gene editing issued in relation to CRISPR-Cas9, the only one to give significant regard to the potential role to be played by human rights is the report by the Nuffield Council on Bioethics. ${ }^{[4]}$ This report departed from the general consensus towards a moratorium, concluding that there are circumstances within which GGE would be permissible, and that there are moral reasons to allow research to continue. In reaching this conclusion, the Nuffield Council report notes that the use of CRISPRCas9 technology intersects with the high premium modern liberal democracies give to the need to respect the reproductive goals of persons seeking to become parents. SA is one such liberal democracy, and the Constitutional Court has recognised that the reproductive rights of parents apply to the use of new reproductive technologies in order to have a child. ${ }^{[45]}$

While bioconservatives may consider GGE an unprecedented intrusion into the destiny of future generations, bioliberal scholars have argued that GGE is in no way meaningfully different from other ways in which parents can influence their children - and as such, there is nothing necessarily ethically impermissible about it. ${ }^{[4]]}$ In a review ${ }^{[46]}$ of recent reports by major ethics bodies in the USA, UK and Germany, respectively, it appears that is a view which is globally reflected, as neither the 2017 report by the National Academies of Sciences, Engineering and Medicine, the 2018 report by the Nuffield Council on Bioethics nor the 2019 report by the German Ethics Council concluded that there was anything inherently unethical about GGE such that it could never be permitted. Accordingly, if the safety and efficacy issues of heritable genome editing can be overcome, there is a compelling case in favour of permitting parents to choose to use this technology, based on human rights. ${ }^{[4]}$

\section{A call for an African perspective on the ethics of germline gene editing}

In addition to the human rights dimensions of gene editing, another real oversight in the current debates around CRISPR-Cas9, which is relevant to $S A$, has been the Eurocentric paradigm within which these issues have been framed. This is problematic because the neglect of the African perspective poses a challenge to the implementation of recommendations for regulating GGE in Africa - as they omit relevant, context-specific factors. For instance, while Western positions appear to be extremely mindful of the possibility of the use of CRISPR-Cas9 being somehow akin to eugenics practices, no such similar historical considerations appear to have significant bearing outside of the USA and Europe, with public opinion polls outside these areas showing a greater public openness to GGE. ${ }^{[48]}$

Moreover, the way in which the debate around GGE has been framed relies on certain normative assumptions - such as the distinction between 'negative selection' for therapeutic purposes, and 
'positive selection' for purposes of enhancement, with the latter being perceived as more ethically dubious. This is because there is said to be no compelling reason for genetic improvement. It is for this reason that ethics statements such as the one issued by the Association for Responsible Research and Ethics in Genome Editing in 2018 ${ }^{[49]}$ claim that genetic modification of the CCR5 gene to prevent children from contracting HIV is a genetic enhancement, and therefore unnecessary and unethical.

While there is clearly no immediate imperative for genetic enhancement in the West, in SA we face a high infectious disease burden and challenges in public healthcare, and socioeconomic challenges have meant that existing treatment has been ineffective and led to deaths that could have been prevented. ${ }^{\left[{ }^{[0]}\right.}$ In the face of several epidemics due to infectious diseases such as HIV/AIDS, there is arguably a strong imperative for exploring any course that could lead to the eradication or mitigation of a disease that claims millions of lives in Africa, even if it amounts to genetic enhancement. This is relevant to the call made by many scientists and ethicists, most notably Lander et al., ${ }^{[51]}$ for a moratorium on GGE.

On the African continent, most states are developing economies dealing with public health challenges caused by infectious diseases. In this context, while concerns about the cost of carelessly pursuing genome modification voiced by bioconservative scholars and echoed by the recent statements by the 2015 World Summit, ${ }^{[7]}$ the US $\mathrm{NIH}^{[8]}$ and the $\mathrm{WHO}^{[9]}$ are well-founded, we ought to be equally wary of the cost of being too cautious. Moratoriums carry a danger of delaying good science, and the longer that delay, the more people who are born, suffer and die without benefiting from a therapeutic intervention that could have had a major impact on their lives. There is, therefore, a strong reason for African states to reconsider the extent to which this imperative ought to influence the determination of whether GGE is ethical - and to do so from an ethical perspective rooted in African perspectives on questions of morality.

\section{Conclusion}

GGE poses several complex legal and ethical questions that raise challenging issues such as whether manipulating the human genome is (ethically and legally) permissible, whether prospective parents are entitled to make decisions regarding the genetic characteristics of their prospective children - including by genome editing, and what the impact of GGE will be on a child born through the use of these technologies. While there are no clear answers to these questions, it is clear that they are not questions that can be ignored, given that safe GGE may be possible in the foreseeable future. Ethical perspectives on these issues clearly vary, and bioconservative scholars voice concerns that many seem to have about issues such as the possible outcomes of GGE on persons born from the use of these technologies. One cannot, however, completely discount GGE in SA, given that at the core, bioliberal arguments in favour of permitting GGE are grounded in the value of freedom upon which our Bill of Rights is founded, and potentially implicate the human rights of several persons. As such, the critical question in SA, from a legal perspective, is not 'should we allow people to modify their future offspring genetically?' but rather 'do we have a good reason to stop them?'.

Acknowledgements. None.

Author contributions. Sole author.
Funding. National Research Foundation, Grant 116275; University of KwaZulu-Natal, African Health Research Flagship Grant.

Conflicts of interest. None.

1. Jinek $\mathrm{M}$, Chylinski $\mathrm{K}$, Fonfara $\mathrm{I}$, et al. A programmable dual-RNA-guided DNA endonuclease in adaptive bacterial immunity. Science 2012;337(6096):816-821. https://doi.org/10.1126/science.1225829

2. Doudna JA, Charpentier E. The new frontier of genome engineering with CRISPRCas9. Science 2014;346(6213):1258096. https://doi.org/10.1126/science.1258096

3. Gaj T, Sirk SJ, Shui Sl, et al. Genome-editing technologies: Principles and applications. Cold Spring Harb Perspect Biol 2016;8(12):1-20. https://doi. org/10.1101/cshperspect.a023754

4. Baliou M, Adamaki M, Kyriakopoulos AM, et al. CRISPR therapeutic tools for complex genetic disorders and cancer (Review). Int J Oncol 2018;53(2):443-468 https://doi.org/10.3892/ijo.2018.4434

5. Warmflash D. Religious beliefs shape our thinking on cloning, stem cells and gene editing. https://geneticliteracyproject.org/2019/11/27/religious-beliefs-shape-ourthinking-on-cloning-stem-cells-and-gene-editing/ (accessed 12 January 2019).

6. Cavaliere G. Genome editing and assisted reproduction: Curing embryos, society or prospective parents? Med Health Care Philos 2018;21(2):215-225. https://doi. org/10.1007/s11019-017-9793-y

7. National Academies of Science Medicine and Engineering. International summit on human genome editing. Washington, DC: National Academies Press, 2015. https://www.nap.edu/catalog/21913/international-summit-on-human-geneediting-a-global-discussion (accessed 24 August 2019).

8. National Institutes of Health. Statement on NIH funding of research using geneediting technologies in human embryos. https://www.nih.gov/about-nih/whowe-are/nih-director/statements/statement-nih-funding-research-using-geneediting-technologies-human-embryos (accessed 24 September 2019).

9. World Health Organization. WHO advisory committee on developing global standards for governance and oversight of human genome editing. Report of the first meeting. Geneva: WHO, 2019. https://www.who.int/ethics/topics/ human-genome-editing/GenomeEditing-FirstMeetingReport-FINAL.pdf?ua=1 (accessed 24 September 2019).

10. Mukherjee S. The Gene: An Intimate History. Large print edition. Farmington Hills: Large Print Press, 2017.

11. Araki M, Ishii T. International regulatory landscape and integration of corrective genome editing into in vitro fertilisation. Reprod Biol Endocrinol 2014;12(1):108120. https://doi.org/10.1186/1477-7827-12-108

12. South Africa. National Health Act No. 61 of 2003.

13. Habermas J. The Future of Human Nature. 1st ed. Cambridge: Polity, 2003.

14. Comfort N. Can we cure genetic diseases without slipping into eugenics? TheNation.com, July 162015.

15. Bailey R. Liberation Biology: The Scientific and Moral Case For The Biotech Revolution. Buffalo: Prometheus, 2005.

16. McGee A. Using the therapy and enhancement distinction in law and policy. Bioethics 2019;34(1):70-80. https://doi.org/10.1111/bioe.12662

17. Mikkelson RB, Frederikson HR, Gjerris M, et al. Genetic protection modifications: Moving beyond the binary distinction between therapy and enhancement for human genome editing. CRISPR J 2019;2(6):362-369. https://doi.org/10.1089/ crispr.2019.0024.18

18. Kass L. Preventing a brave new world. The New Republic Online, June 212001.

19. Paul DB. Genetic engineering and eugenics: The uses of history. In Baillie HW, Casey TK. (editors). Is human nature obsolete? Genetics, Bioengineering, and the Future of the Human Condition. Cambridge: MIT Press, 2004:123-152.

20. Baillie HW. Aristotle and genetic engineering: The uncertainty of excellence. The uses of history. In: Baillie HW, Casey TK (editors). Is Human Nature Obsolete? Genetics, Bioengineering, and The Future of the Human Condition. Cambridge: MIT Press, 2004:209-232.

21. Harris J. Clones, genes and human rights. In: Burley J (editor), The Genetic Revolution and Human Rights: The Oxford Amnesty Lectures 1998. 1st ed. Oxford: Oxford University Press, 1999:67-94.

22. Rabinow P. Life science: Discontents and consultations. In: Baillie HW, Casey TK (editors). Is Human Nature Obsolete? Genetics, Bioengineering, and The Future of the Human Condition. Cambridge: MIT Press, 2004:99-132.

23. Mauron A. Is the genome the secular equivalent of the soul? Science 2001;291(5505):831-832.

24. Sen A. Identity and Violence: The Illusion of Destiny. Dehli: Penguin Books India, 2007

25. Bosley KS, Botchan M, Bredenoord AL, et al. CRISPR germline engineering - the community speaks. Nat Biotechnol 2015;33(5):478-486

26. Fukuyama F. Our Posthuman Future: Consequences of the Biotechnology Revolution. Reprint ed. London: Picador, 2003. 
27. Jordaan DW. Antipromethean fallacies: A critique of Fukuyama's bioethics. Biotechnol Law Rep 2009;28(5):577-578. https://doi.org/10.1089/blr.2009.9915

28. Caufield T. Cloning and genetic determinism - a call for consistency. Nature Biotechnol 2001;19(5):403.

29. Watson JD. Moving toward the clonal man. The Atlantic, May 1971.

30. Hopkins PD. Bad copies: How popular media represent cloning as an ethical problem. Hastings Cent Rep 1998;28(2):6-13.

31. Singer P. Animal Liberation. New York: Avon Books, 1977.

32. Mill JS. Three essays on religion: Nature, the utility of religion, theism. Revised ed. Buffalo: Prometheus, 1998

33. Taleb NN, Read R, Douady R, Norman J, Bar-Yam Y. The precautionary principle (with application to the genetic modification of organisms). Extreme Risk Initiative. NYU School of Engineering Working Paper Series. 2014.

34. Koplin JJ, Gyngell C, Savulescu J. Germline gene editing and the precautionary principle. Bioethics 2019:1-11. https://doi.org/10.1111/bioe.12609

35. Cooper D, Grinder B. Probability, Gambling and the Origins of Risk Management. New York: Museum of American Finance, 2009.

36. Dworkin R. Sovereign Virtue: The Theory and Practice of Equality. Trade Paperback edition. Cambridge: Harvard University Press, 2002.

37. Stock G. Redesigning Humans: Choosing Our Genes, Changing Our Future. Boston: Mariner Books, 2003.

38. Mill JS. On Liberty and the Subjection of Women. 1st ed. London: Penguin Classics, 2007.

39. Robertson JA. Procreative liberty in the era of genomics. Am J Law Med 2003;29(4):439-444.

40. Robertson JA. Children of Choice: Freedom and the New Reproductive Technologies. Princeton: Princeton University Press, 1996.

41. Silver LM. Remaking Eden: How Genetic Engineering and Cloning will Transform the American Family. New York: Ecco, 2007.
42. Savulescu J, Pugh J, Douglas T, Gyngell C. The moral imperative to continue gene editing research on human embryos. Protein Cell 2015;6(7):476-478. https://doi. org/10.1007/s13238-015-0184-y

43. Constitution of the Republic of South Africa. 1996.

44. Nuffield Council on Bioethics. Genome editing and human reproduction. London: Nuffield Council on Bioethics, 2018. http://nuffieldbioethics.org/wpcontent/uploads/Genome-editing-and-human-reproduction-FINAL-website. pdf (accessed 24 September 2019).

45. AB v Minister of Social Development 2016 (43) ZACC, 2017 (3) SA 570 (CC).

46. Greely HT. Human germline genome editing: An assessment. CRISPR J 2019;2(5):253-265. https://doi.org/10.1089/crispr.2019.0038

47. Thaldar DW, Shozi B. Procreative non-maleficence: A South African human rights perspective on heritable human genome editing. CRISPR J 2020;3(1):32-36. https://doi.org/10.1089/crispr.2019.0036

48. Centre for Genetics and Society. Summary of public opinion polls. 2018. https:// www.geneticsandsociety.org/internal-content/cgs-summary-public-opinionpolls\#igmdata (accessed 25 August 2019).

49. Association for Responsible Research and Innovation in Genome Editing. Statement from ARRIGE Steering Committee on the possible first gene-edited babies. 2019. http://arrige.org/ARRIGE_statement_geneeditedbabies.pdf (accessed 17 September 2019).

50. Joint United Nations Programme on HIV/AIDS (UNAIDS). 2018. https://www unaids.org/en/regionscountries/countries/southafrica (accessed 25 September 2019).

51. Lander ES, Baylis F, Zhang F, et al. Adopt a moratorium on heritable genome editing. Nature 2019;567(7747):165-168.

Accepted 5 May 2020. 